\title{
Stenotrophomonas terrae sp. nov. and Stenotrophomonas humi sp. nov., two nitrate-reducing bacteria isolated from soil
}

\author{
Correspondence \\ Kim Heylen \\ Kim.Heylen@UGent.be
}

\author{
Kim Heylen, Bram Vanparys, Filip Peirsegaele, Liesbeth Lebbe \\ and Paul De Vos
}

\author{
Laboratory of Microbiology, Department of Biochemistry, Physiology and Microbiology, \\ Ghent University, K.L. Ledeganckstraat 35, B-9000 Gent, Belgium
}

In the large-scale phenotypic study of Stanier et al. (1966), Pseudomonas maltophilia was regarded as an authentic member of the genus Pseudomonas. Subsequent allocation of this species to the genus Xanthomonas as Xanthomonas maltophilia was supported by rRNA hybridization data (Swings et al., 1983), but resulted in a reclassification at the genus level into Stenotrophomonas Palleroni and Bradbury 1993, the genus being differentiated from both Pseudomonas and Xanthomonas based on various taxonomic methods. At the time of writing, the genus Stenotrophomonas comprises six recognized species, Stenotrophomonas maltophilia (Palleroni \& Bradbury, 1993), S. nitritireducens (Finkmann et al., 2000), S. acidaminiphila (Assih et al., 2002), S. rhizophila (Wolf et al., 2002), S. koreensis (Yang et al., 2006) and S. dokdonensis (Yoon et al., 2006).

A cultivation-dependent study on soil used selective isolation conditions to focus on the microbial diversity involved in nitrogen removal. Within the dominant gammaproteobacterial nitrate reducers, seven isolates were retrieved on the defined isolation medium G3M12 - with ethanol as carbon source and nitrate as nitrogen source

Abbreviation: RFLP, restriction fragment length polymorphism.

The GenBank/EMBL/DDBJ accession numbers for the 16S rRNA gene sequences of strains R-32768 ${ }^{\top}$ and $\mathrm{R}-32729^{\top}$ are $\mathrm{AM} 403589$ and AM403587, respectively.

A table giving the cellular fatty acid compositions of strains R-32768 ${ }^{\top}$ and $\mathrm{R}-32729^{\top}$ and their closest phylogenetic neighbours is available as supplementary material with the online version of this paper.
(Heylen et al., 2006) - that could be assigned to Stenotrophomonas based on partial 16S rRNA gene sequences. Three of these isolates, R-32746, R- $32768^{\mathrm{T}}$ and $\mathrm{R}-32729^{\mathrm{T}}$, could possibly represent novel species based on partial 16S rRNA gene sequence similarities and were analysed further in a polyphasic study. With all of the techniques employed the strains were identified as not representing S. maltophilia (recommended comparison). The type strains of all recognized Stenotrophomonas species, except that for the phylogenetically most distant $S$. dokdonensis (Fig. 1), were re-examined for phenotyping, chemotaxonomy and biochemical analysis to guarantee comparable data. In addition, S. maltophilia LMG 22072, which was the proposed type strain of Stenotrophomonas africana, was included [Stenotrophomonas africana was found to be a later heterotypic synonym of Stenotrophomonas maltophilia (Coenye et al., 2004a)].

In order to avoid studying duplicate isolates of the same strain, genotyping by random amplified polymorphic DNA PCR analysis (Coenye et al., 2002) and repetitive sequencebased PCR analysis with REP and BOX primers (Heyrman et al., 2005) were carried out. The three fingerprint methods generated identical patterns for isolates R-32746 and R-32768 ${ }^{\mathrm{T}}$, but showed clear genetic differences for isolate R-32729 ${ }^{\mathrm{T}}$ (data not shown). As R-32746 and R$32768^{\mathrm{T}}$ are most probably members of a single strain, only $\mathrm{R}-32768^{\mathrm{T}}$ was subject to further study. The DNA G $+\mathrm{C}$ contents of strains R-32768 ${ }^{\mathrm{T}}$ and R- $32729^{\mathrm{T}}$, based on single HPLC determinations (Mesbah et al., 1989), were 65 and 


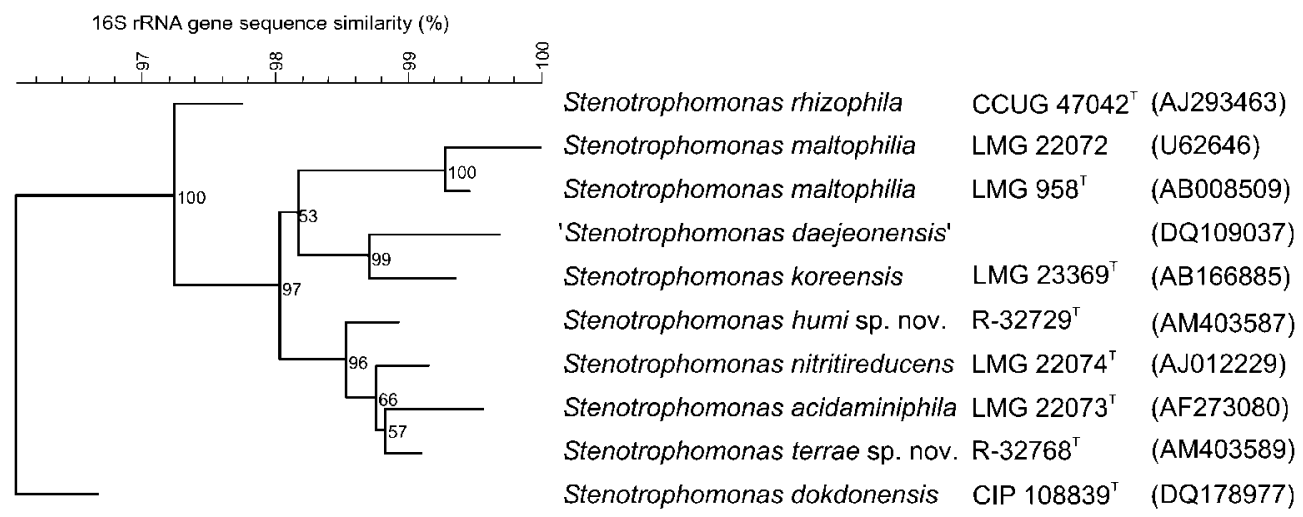

Fig. 1. Phylogenetic dendrogram of $16 \mathrm{~S}$ rRNA gene sequences showing the position of strains $R-32729^{\top}$ and $R-32768^{\top}$ among the type strains of Stenotrophomonas species. Neighbour-joining clustering was performed with BioNumerics version 4.6. Bootstrap values (expressed as percentages of 1000 replicates) are shown at branch points. EMBL accession numbers are shown in parentheses. 'Stenotrophomonas daejeonensis' is also included, but this name has not been validly published and only the $16 \mathrm{~S}$ rRNA gene sequence is available.

$64 \mathrm{~mol} \%$, respectively. Nearly complete $16 \mathrm{~S}$ rRNA gene sequences of strains $\mathrm{R}-32768^{\mathrm{T}}$ and $\mathrm{R}-32729^{\mathrm{T}}$ were determined as described by Vanparys et al. (2005). Phylogenetic analysis was performed by using BioNumerics software version 4.6 after multiple alignment with CLUSTAL_X (Thompson et al., 1997). Cluster analysis via the neighbour-joining algorithm with or without corrections for evolutionary distances as described by Jukes \& Cantor (1969) and Kimura (1980) were in agreement with the maximum-parsimony and maximum-likelihood methods. Strains R-32729 $9^{\mathrm{T}}$ and $\mathrm{R}-32768^{\mathrm{T}}$ clustered together with $S$. nitritireducens LMG $22074^{\mathrm{T}}$ and S. acidaminiphila LMG $22073^{\mathrm{T}}$, supported by high bootstrap values (Fig. 1). Therefore, DNA-DNA hybridization experiments were performed within this cluster, by using a modification of the microplate method of Ezaki et al. (1989) as described by Willems et al. (2001). A hybridization temperature of $45{ }^{\circ} \mathrm{C}$ (calculated with correction for the presence of $50 \%$ formamide) was used. Strains R-32768 ${ }^{\mathrm{T}}$ and R-32729 showed a mean DNA-DNA relatedness of $44.2 \pm 2.8 \%$ ( $n=2$ for all determinations) with each other. Strain R$32768^{\mathrm{T}}$ showed a mean DNA-DNA relatedness of $41.3 \pm 7$ and $35.8 \pm 4.7 \%$ with $S$. nitritireducens LMG $22074^{\mathrm{T}}$ and $S$. acidaminiphila LMG $22073^{\mathrm{T}}$, respectively. Strain R-32729 showed a mean DNA-DNA relatedness of $37.2 \pm 6.6$ and $38.1 \pm 5.1 \%$ with S. nitritireducens LMG $22074^{\mathrm{T}}$ and S. acidaminiphila LMG $22073^{\mathrm{T}}$, respectively. These results confirmed that strains $\mathrm{R}-32729^{\mathrm{T}}$ and $\mathrm{R}-32768^{\mathrm{T}}$ represent two novel genotypic species.

Cell morphology, motility and possible sporulation were investigated using phase-contrast microscopy at a magnification of $1000 \times$ with cells grown on tryptone soy agar (TSA; Oxoid) for $48 \mathrm{~h}$ at $28{ }^{\circ} \mathrm{C}$. Cells were Gram stained and examined for catalase and oxidase activity. Utilization of carbon sources and enzyme production were tested with the API $20 \mathrm{NE}\left(48 \mathrm{~h}, 28{ }^{\circ} \mathrm{C}\right)$, API ZYM $\left(4 \mathrm{~h}, 28{ }^{\circ} \mathrm{C}\right)$ and API $50 \mathrm{CH}$ (inoculated with AUX medium, $48 \mathrm{~h}, 28{ }^{\circ} \mathrm{C}$ ) systems (bioMérieux), according to the manufacturer's instruction. Strains R-32729 ${ }^{\mathrm{T}}$ and R-32768 ${ }^{\mathrm{T}}$ were identified as not representing $S$. maltophilia with these conventional phenotypic taxonomic tests. The temperature range (at 4 , $15,28,37$ and $\left.52{ }^{\circ} \mathrm{C}\right), \mathrm{pH}$ range $\left(4.5-10.5\right.$ at $28{ }^{\circ} \mathrm{C}$ ) and salinity range $\left(0.5-5 \% \mathrm{w} / \mathrm{v}\right.$, at $\left.28{ }^{\circ} \mathrm{C}\right)$ for growth were recorded after incubation for $72 \mathrm{~h}$ on TSA. The ability to reduce nitrate was tested, as described by Smibert \& Krieg (1994), after growth for 2 weeks on tryptone soy broth (TSB; Oxoid) supplemented with $10 \mathrm{mM}$ potassium nitrate at $37{ }^{\circ} \mathrm{C}$ and on liquid G3M11 medium containing $18 \mathrm{mM}$ potassium nitrate and $22.5 \mathrm{mM}$ ethanol (Heylen et al., 2006) at $20^{\circ} \mathrm{C}$ - the solid variant of the latter was used as isolation medium for the Stenotrophomonas strains. For all strains, these results were in agreement with the nitrate reduction test in the API 20NE system. Lipolytic activity was tested via hydrolysis of Tween 80 , as described by Sierra (1957). The phenotypic and biochemical characteristics of all strains tested are given in Table 1.

Cells of all strains were incubated under identical conditions for $24 \mathrm{~h}$ at $28{ }^{\circ} \mathrm{C}$ on TSA. One loopful of cells was harvested, fatty acid methyl esters were prepared and these were then extracted according to the standardized protocol of the Microbial Identification System (MIS; Microbial ID Inc.). The MIDI with the TSBA50 database was used for identification. All test strains contained the fatty acids iso- $\mathrm{C}_{11: 0}$, iso- $\mathrm{C}_{11: 0} 3-\mathrm{OH}$ and iso- $\mathrm{C}_{13: 0} 3-\mathrm{OH}$ characteristic for the genus Stenotrophomonas (Assih et al., 2002; Yang et al., 1993), and iso- $\mathrm{C}_{15: 0}$ as the dominant fatty acid. Strains R-32768 ${ }^{\mathrm{T}}$ and $\mathrm{R}-32729^{\mathrm{T}}$ had highly similar fatty acid profiles, only differing in the amount of specific components, and mostly containing iso-branched compounds. Characteristic fatty acids for strains R- $32768^{\mathrm{T}}$ 
Table 1. Physiological characteristics of strains $R-32768^{\top}$ and $R-32729^{\top}$ and their closest phylogenetic neighbours in the genus Stenotrophomonas

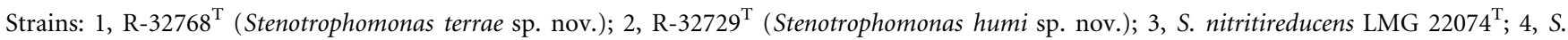
acidaminiphila LMG $22073^{\mathrm{T}}$; 5, S. koreensis LMG $23369^{\mathrm{T}}$; 6, S. maltophilia LMG 958 ${ }^{\mathrm{T}}$; 7, S. maltophilia LMG 22072; 8, S. rhizophila CCUG 47042 ${ }^{\mathrm{T}}$. The type strain of $S$. dokdonensis is not included. Data are from this study unless indicated. +, Positive; w, weakly positive; - , negative; v, variable. All strains characterized in this study are positive for catalase, alkaline phosphatase, esterase, esterase lipase, trypsin, acid phosphatase and glucose fermentation. All are negative for lipase, cystine arylamidase, chymotrypsin, $\alpha$-galactosidase, $\beta$-galactosidase, $\beta$-glucuronidase, $\alpha$-glucosidase, $\alpha$ mannosidase, $\alpha$-fucosidase, indole production, arginine dihydrolase, urease, $\beta$-galactosidase, assimilation of caprate, adipate, phenyl acetate, glycerol, erythritol, D-arabinose, L-arabinose, D-ribose, L-xylose, D-adonitol, methyl $\beta$-D-xylopyranoside, D-galactose, L-sorbose, L-rhamnose, dulcitol, inositol, D-mannitol, D-sorbitol, methyl $\alpha$-D-mannopyranoside, methyl $\alpha$-D-glucopyranoside, inulin, D-melezitose, D-raffinose, starch, xylitol, D-lyxose, D-tagatose, D-fucose, L-fucose, D-arabitol, L-arabitol, potassium gluconate, potassium 2-ketogluconate and potassium 5ketogluconate.

\begin{tabular}{|c|c|c|c|c|c|c|c|c|}
\hline Characteristic & 1 & 2 & 3 & 4 & 5 & 6 & 7 & 8 \\
\hline Hydrolysis of Tween 80 (lipolytic activity) & + & - &,$-+^{\star}$ &,$-+\dagger$ & + & + & - & + \\
\hline Denitrification & - & - & $\mathrm{v} \S$ &,$-+\dagger$ & - & - & - & - \\
\hline Oxidase & + & + & + & + &,-+11 & - & - & + \\
\hline Leucine arylamidase & + & - & - & - & - & - & + & + \\
\hline Naphthol-AS-BI-phosphohydrolase & + & + & + & + & - & + & + & + \\
\hline$\beta$-Glucosidase & - & - & - & - & - & $\mathrm{W}$ & + & + \\
\hline$N$-Acetyl- $\beta$-glucosaminidase & - & + & + & + & - & - & - & - \\
\hline$\beta$-Glucosidase (aesculin hydrolysis) & $\mathrm{w}$ & - & - & + & - & + & + & + \\
\hline Protease (gelatin hydrolysis) & + & $\mathrm{w}$ & - & - & + & + & + & + \\
\hline \multicolumn{9}{|l|}{ Assimilation of: } \\
\hline D-Lactose & - & - & - & - & - &,$-+\#$ & $\mathrm{w},+\#$ & - \\
\hline Maltose & + & + & - & + & - & + & + & + \\
\hline D-Mannose & + & + & - & + & - & + & + & + \\
\hline D-Melibiose & - & - & - & - & - & - & + & - \\
\hline Sucrose & - & - & - & - & - & + & + & - \\
\hline Trehalose & - & - & - & - & - &,$-+\#$ & + &,-+9 \\
\hline D-Turanose & - & - & - & - & - & - & + &,-+9 \\
\hline D-Xylose & - & - & - & - & - & - & - &,-+9 \\
\hline Citrate & + & + & + & - & - & + & + & + \\
\hline Malate & - & + & - & - & - & + & + & + \\
\hline Inositol & $\mathrm{w}$ & - & - & - & - & - & - & - \\
\hline
\end{tabular}

${ }^{\star}$ Data from Finkmann et al. (2000).

$\dagger$ Data from Assih et al. (2002).

$\ddagger$ LMG $22073^{\mathrm{T}}$ reduces nitrate when grown on TSA supplemented with $10 \mathrm{mM}$ nitrate, but does not reduce nitrate when grown on defined growth medium G3M11.

§LMG $22074^{\mathrm{T}}$ cannot denitrify starting from nitrate, only from nitrite.

IIData from Yang et al. (2006).

SData from Wolf et al. (2002).

\#Data from Drancourt et al. (1997). 
and $\mathrm{R}-32729^{\mathrm{T}}$ were iso- $\mathrm{C}_{14: 0}(14.2$ and $15.7 \%$, respectively), iso- $\mathrm{C}_{15: 1}$ (4.6 and $\left.2 \%\right)$, iso- $\mathrm{C}_{16: 0}$ (8 and $12.7 \%$ ) and iso- $\mathrm{C}_{17: 1} \omega 9 c(7.2$ and $4.6 \%)$. The complete fatty acid profiles of all the test strains are available as Supplementary Table S1 in IJSEM Online. Numerical analysis of the fatty acid profiles (Fig. 2) revealed that strains R-32768 ${ }^{\mathrm{T}}$ and R$32729^{\mathrm{T}}$ formed a distinct cluster, supported with a high cophenetic correlation, and grouping closely with their phylogenetically nearest neighbours $S$. nitritireducens LMG $22074^{\mathrm{T}}$ and S. acidaminophila LMG $22073^{\mathrm{T}}$. The MIDI fatty acid identification system showed no relevant matches for strains $\mathrm{R}-32768^{\mathrm{T}}$ and $\mathrm{R}-32729^{\mathrm{T}}$. However, the position of these strains within the group Stenotrophomonas-Xanthomonas was further confirmed by comparing the fatty acid profiles qualitatively and quantitatively with an in-house database containing over 60000 fatty acid profiles. The failure of the MIDI identification system to allocate these strains within the genus Stenotrophomonas was also observed for several highly similar profiles of members of the genus Xanthomonas (K. Heylen and P. De Vos, unpublished data) and reported previously for S. acidaminiphila by Assih et al. (2002).

Coenye et al. (2004b) and Hauben et al. (1999) suggested that, prior to their description, the relationship of novel species within the genus Stenotrophomonas with the heterogeneous species $S$. maltophilia should be investigated. gyrB-restriction fragment length polymorphism (RFLP) analysis of $S$. maltophilia strains has proven to be in accordance with DNA-DNA hybridization results (Coenye et al.., 2004b). Therefore, the gyrB-RFLP profiles of strains $\mathrm{R}-32768^{\mathrm{T}}$ and $\mathrm{R}-32729^{\mathrm{T}}$ were analysed as described by Coenye et al. (2004b), together with an additional set of Stenotrophomonas strains representing gyrB-RFLP clusters A, B, C, E, F, G and I. Strains R-32768 ${ }^{\mathrm{T}}$ and R- $32729^{\mathrm{T}}$ did not render a gyrB amplicon, even after several repeats. The same observation was made for two Stenotrophomonas spp. strains (T. Coenye, personal communication). It was concluded that this approach was not suitable for the novel strains, which, therefore, must differ from the strains that did render gyrB amplicons.

To substantiate further that strains R- $32729^{\mathrm{T}}$ and R- $32768^{\mathrm{T}}$ do not represent S. maltophilia, SDS-PAGE analysis of whole-cell proteins was performed on all strains included in the gyrB-RFLP trials. Aerobically grown cells were harvested after incubation at $28{ }^{\circ} \mathrm{C}$ for $24 \mathrm{~h}$ on phosphatebuffered nutrient agar ( $\mathrm{pH}$ 6.8). An SDS-PAGE banding pattern for all strains was generated according to the standardized protocol of Pot et al. (1994). Pearson's correlation similarity coefficients were clustered with UPGMA and analysed with the co-phenetic correlation method in BioNumerics version 4.6 (Fig. 3). The grouping of the whole-cell protein profiles was supported by high cophenetic correlation values but did not correlate with the gyrB-RFLP grouping, except for gyrB-RFLP cluster G. Strains R-32729 $9^{\mathrm{T}}$ and $\mathrm{R}-32768^{\mathrm{T}}$ did not group together. Their phylogenetically closest neighbours, S. nitritireducens LMG $22074^{\mathrm{T}}$ and S. acidaminophila LMG $22073^{\mathrm{T}}$, together with strain R-12772, grouped separately from all other Stenotrophomonas strains.

Based on the data presented from the polyphasic study, strains R-32768 ${ }^{\mathrm{T}}$ and $\mathrm{R}-32729^{\mathrm{T}}$ are considered to represent two novel species of the genus Stenotrophomonas, for which the names Stenotrophomonas terrae sp. nov. and Stenotrophomonas humi sp. nov. are proposed.

\section{Description of Stenotrophomonas terrae sp. nov.}

Stenotrophomonas terrae (ter'rae. L. gen. n. terrae of/from soil).

After $24 \mathrm{~h}$ incubation at $28{ }^{\circ} \mathrm{C}$ on TSA, colonies are irregular in shape and light yellow. Cells are motile, nonspore-forming, Gram-negative rods. Catalase- and oxidasepositive. Growth is observed at $15-37{ }^{\circ} \mathrm{C}$ (but not at 4 or $52{ }^{\circ} \mathrm{C}$ ), at $\mathrm{pH} 5-10.5$ (but not at $\mathrm{pH} 4.5$ ) and at salinity of $0.5-5 \%$. Anaerobic growth is possible through nitrate reduction. Enzyme activities and carbon utilization results are given in Table 1. Can be differentiated from the type strains of its closest phylogenetic neighbours, S. humi, $S$. nitritireducens and $S$. acidaminiphila, by SDS-PAGE analysis and the presence of leucine arylamidase and protease, the assimilation of glucose and the absence of $N$-acetyl- $\beta$-glucosaminidase.

The type strain is $\mathrm{R}-32768^{\mathrm{T}} \quad\left(=\mathrm{LMG} \quad 23958^{\mathrm{T}}=\mathrm{DSM}\right.$ $18941^{\mathrm{T}}$ ), which has a DNA $\mathrm{G}+\mathrm{C}$ content of $65 \mathrm{~mol} \%$, and was isolated from soil from a university test field in Ghent, Belgium.

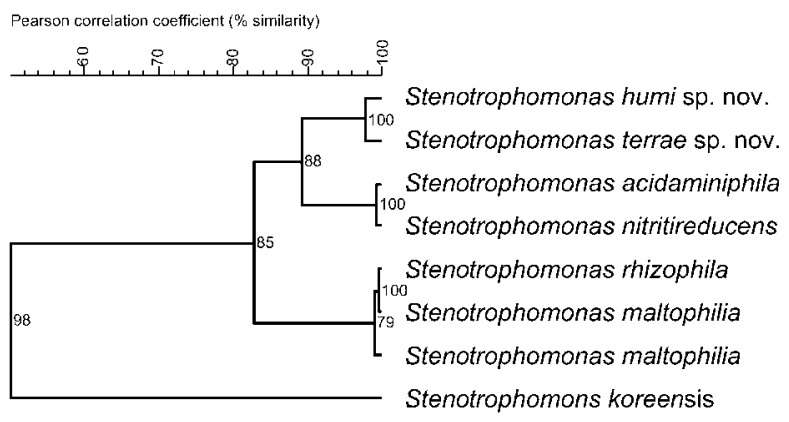

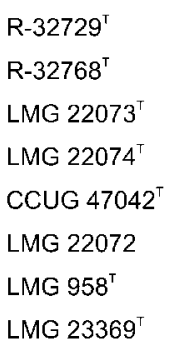

Fig. 2. Numerical comparison of the fatty acid profiles obtained. UPGMA clustering with Pearson's correlation similarity coefficients was performed by using BioNumerics version 4.6. The co-phenetic correlation tool, which distinguishes reliable from unreliable subclusters, was used for cluster significance analysis. 


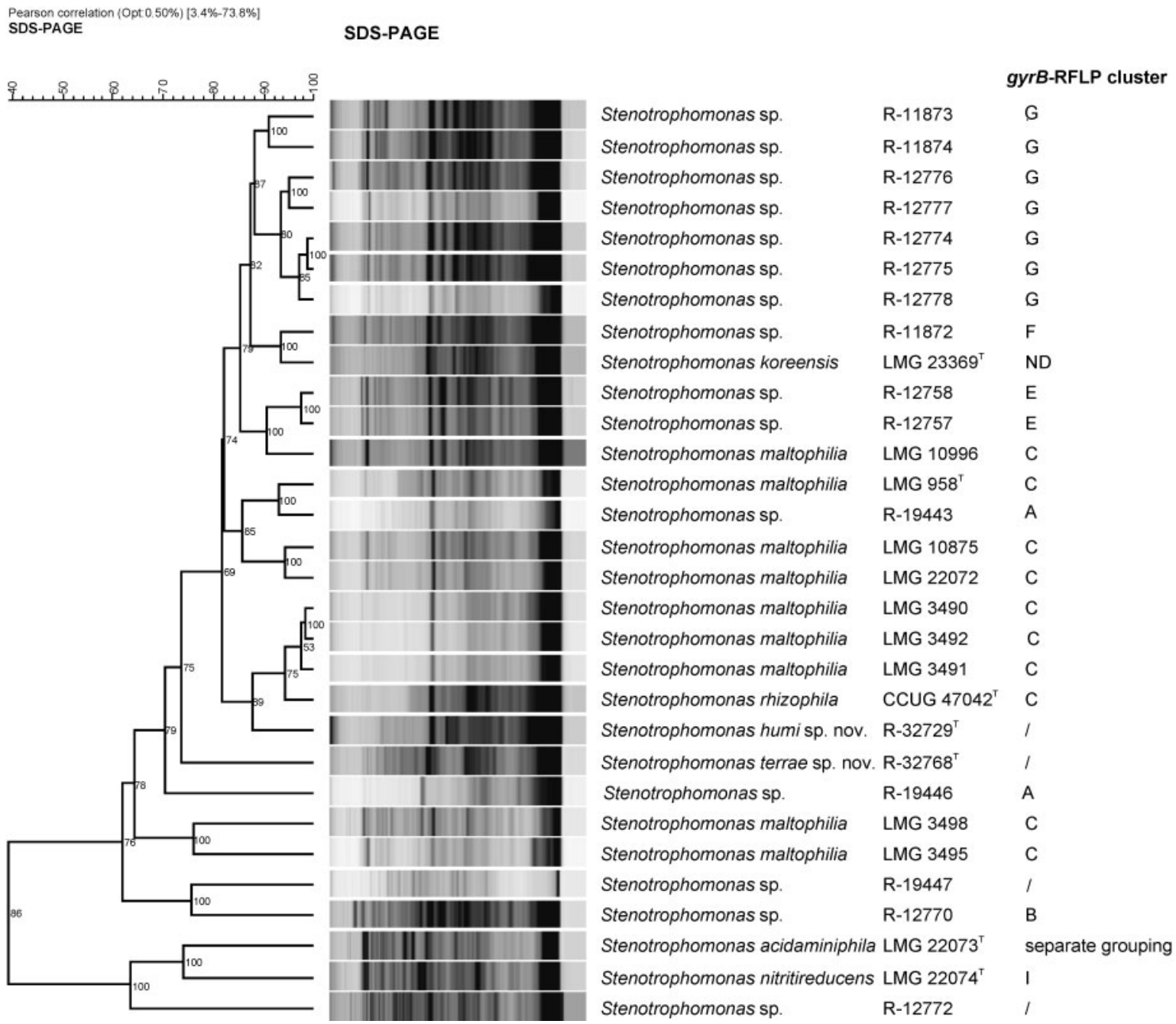

Fig. 3. Grouping of normalized digitized SDS-PAGE patterns. UPGMA clustering with Pearson's correlation similarity coefficients was performed by using BioNumerics version 4.6. The co-phenetic correlation tool, which distinguishes reliable from unreliable subclusters, was used for cluster significance analysis. The identification of non-type strains and the assignment to gyrB-RFLP clusters were taken from Coenye et al. (2004b).

\section{Description of Stenotrophomonas humi sp. nov.}

Stenotrophomonas humi (hu'mi. L. gen. n. humi of/from soil).

After $24 \mathrm{~h}$ incubation at $28{ }^{\circ} \mathrm{C}$ on TSA, colonies are round, smooth and beige. Cells are motile, non-spore-forming, Gram-negative rods. Catalase- and oxidase-positive. Growth is observed at $15-37{ }^{\circ} \mathrm{C}$ (but not at 4 or $52{ }^{\circ} \mathrm{C}$ ), at pH 5-10.5 (but not at $\mathrm{pH} 4.5$ ) and at salinity of $0.5-4 \%$ (but not at $5 \%$ ). Anaerobic growth is possible through nitrate reduction. Enzyme activities and carbon utilization results are given in Table 1. Can be differentiated from the type strains of its closest phylogenetic neighbours, S. terrae, S. nitritireducens and S. acidaminiphila, by SDS-PAGE analysis and the assimilation of malate.
The type strain is $\mathrm{R}-32729^{\mathrm{T}} \quad\left(=\mathrm{LMG} \quad 23959^{\mathrm{T}}=\mathrm{DSM}\right.$ $18929^{\mathrm{T}}$ ), which has a DNA G+C content of $64 \mathrm{~mol} \%$, and was isolated from soil from a university test field in Ghent, Belgium.

\section{Acknowledgements}

This work was supported by project G.O.A. 1205073 (2003-2008) of the 'Ministerie van de Vlaamse Gemeenschap, Bestuur Wetenschappelijk Onderzoek' (Belgium) and FWO project G20156.02.

\section{References}

Assih, E. A., Ouattara, A. S., Thierry, S., Cayol, J.-L., Labat, M. \& Macarie, H. (2002). Stenotrophomonas acidaminiphila sp. nov., a 
strictly aerobic bacterium isolated from an upflow anaerobic sludge blanket (UASB) reactor. Int J Syst Evol Microbiol 52, 559-568.

Coenye, T., Spilker, T., Martin, A. \& LiPuma, J. J. (2002). Comparative assessment of genotyping methods for epidemiologic study of Burkholderia cepacia Genomovar III. J Clin Microbiol 40, 3300-3307.

Coenye, T., Vanlaere, E., Falsen, E. \& Vandamme, P. (2004a). Stenotrophomonas africana Drancourt et al. 1997 is a later synonym of Stenotrophomonas maltophilia (Hugh 1981) Palleroni and Bradbury 1993. Int J Syst Evol Microbiol 54, 1235-1237.

Coenye, T., Vanlaere, E., LiPuma, J. J. \& Vandamme, P. (2004b). Identification of genomic groups in the genus Stenotrophomonas using gyrB RFLP analysis. FEMS Immunol Med Microbiol 40, 181-185.

Drancourt, M., Bollet, C. \& Raoult, D. (1997). Stenotrophomonas africana sp. nov., an opportunistic human pathogen in Africa. Int $J$ Syst Bacteriol 47, 160-163.

Ezaki, T., Hashimoto, Y. \& Yabuuchi, E. (1989). Fluorometric deoxyribonucleic acid-deoxyribonucleic acid hybridization in microdilution wells as an alternative to membrane filter hybridization in which radioisotopes are used to determine genetic relatedness among bacterial strains. Int J Syst Bacteriol 39, 224-229.

Finkmann, W., Altendorf, K., Stackebrandt, E. \& Lipski, A. (2000). Characterization of $\mathrm{N}_{2} \mathrm{O}$-producing Xanthomonas-like isolates from biofilters as Stenotrophomonas nitritireducens sp. nov., Luteimonas mephitis gen. nov., sp. nov. and Pseudoxanthomonas broegbernensis gen. nov., sp. nov. Int J Syst Evol Microbiol 50, 273-282.

Hauben, L., Vauterin, L., Moore, E. R. B., Hoste, B. \& Swings, J. (1999). Genomic diversity of the genus Stenotrophomonas. Int J Syst Bacteriol 49, 1749-1760.

Heylen, K., Vanparys, B., Wittebolle, L., Verstraete, W., Boon, N. \& De Vos, P. (2006). Cultivation of denitrifying bacteria: optimisation of isolation conditions and diversity study. Appl Environ Microbiol 72, 2637-2643.

Heyrman, J., Verbeeren, J., Schumann, P., Swings, J. \& De Vos, P. (2005). Six novel Arthrobacter species isolated from deteriorated mural paintings. Int J Syst Evol Microbiol 55, 1457-1464.

Jukes, T. H. \& Cantor, C. R. (1969). Evolution of protein molecules. In Mammalian Protein Metabolism, pp. 21-132. Edited by H. N. Munro. New York: Academic Press.

Kimura, M. (1980). A simple method for estimating evolutionary rates of base substitutions through comparative studies of nucleotide sequences. J Mol Evol 16, 111-120.

Mesbah, M., Premachandran, U. \& Whitman, W. B. (1989). Precise measurement of the $\mathrm{G}+\mathrm{C}$ content of deoxyribonucleic acid by highperformance liquid chromatography. Int J Syst Bacteriol 39, 159-167.
Palleroni, N. J. \& Bradbury, J. F. (1993). Stenotrophomonas, a new bacterial genus for Xanthomonas maltophilia (Hugh 1980) Swings et al. 1983. Int J Syst Bacteriol 43, 606-609.

Pot, B., Vandamme, P. \& Kersters, K. (1994). Analysis of electrophoretic whole-organism protein fingerprints. In Chemical Methods in Prokaryotic Systematics, pp. 493-521. Edited by M. Goodfellow \& A. G. O’Donnell. Chichester: Wiley.

Sierra, G. (1957). A simple method for the detection of lipolytic activity of micro-organisms and some observations on the influence of the contact between cells and fatty substrates. Antonie van Leeuwenhoek 23, 15-22.

Smibert, R. M. \& Krieg, N. R. (1994). Phenotypic characterization. In Methods for General and Molecular Bacteriology, pp. 623-624. Edited by P. Gerhardt, R. G. E. Murray, W. A. Wood \& N. R. Krieg, Washington, DC: American Society for Microbiology.

Stanier, R. Y., Palleroni, N. J. \& Doudoroff, M. (1966). The aerobic pseudomonads: a taxonomic study. J Gen Microbiol 43, 159-271.

Swings, J., De Vos, P., Van den Mooter, M. \& De Ley, J. (1983). Transfer of Pseudomonas maltophilia Hugh 1981 to the genus Xanthomonas as Xanthomonas maltophilia (Hugh 1981) comb. nov. Int J Syst Bacteriol 33, 409-413.

Thompson, J. D., Gibson, T. J., Plewniak, F., Jeanmougin, F. \& Higgins, D. G. (1997). The CLUSTAL_X windows interface: flexible strategies for multiple sequence alignment aided by quality analysis tools. Nucleic Acids Res 25, 4876-4882.

Vanparys, B., Heylen, K., Lebbe, L. \& De Vos, P. (2005). Pedobacter caeni sp. nov., a novel species isolated from a nitrifying inoculum. Int J Syst Evol Microbiol 55, 1315-1318.

Willems, A., Doignon-Bourcier, F., Goris, J., Coopman, R., de Lajudie, P., de Vos, P. \& Gillis, M. (2001). DNA-DNA hybridization study of Bradyrhizobium strains. Int J Syst Evol Microbiol 51, 1315-1322.

Wolf, A., Fritze, A., Hagemann, M. \& Berg, G. (2002). Stenotrophomonas rhizophila sp. nov., a novel plant-associated bacterium with antifungal properties. Int J Syst Evol Microbiol 52, 1937-1944.

Yang, P., Vauterin, L., Vancanneyt, M., Swings, J. \& Kersters, K. (1993). Application of fatty acid methyl esters for the taxonomic analysis of the genus Xanthomonas. Syst Appl Microbiol 16, 47-71.

Yang, H.-C., Im, W.-T., Kang, M. S., Shin, D.-Y. \& Lee, S.-T. (2006). Stenotrophomonas koreensis sp. nov., isolated from compost in South Korea. Int J Syst Evol Microbiol 56, 81-84.

Yoon, J.-H., Kang, S.-J., Oh, H. W. \& Oh, T.-K. (2006). Stenotrophomonas dokdonensis sp. nov., isolated from soil. Int J Syst Evol Microbiol 56, 1363-1367. 